\title{
Study on Impact of Hardness of Sole on Force on Feet during Active Falling
}

\author{
Sicheng $\mathrm{Ke}^{1}$, Hong Xie ${ }^{1,}{ }^{*}$, Guangwu Sun ${ }^{1}$, Jiecong $\mathrm{Li}^{1}$ \\ ${ }^{1}$ College of Fashion, Shanghai University of Engineering Science, Shanghai, China. \\ *Xiehong99618@126.com (Hong Xie).
}

Keywords: Active Falling, sole, force on feet, shock absorption.

\begin{abstract}
The purpose is to study effect of sole on force on feet as an additional factor when human body actively falls at different heights. Methods: 12 male subjects respectively wore three pairs of shoes with different cushioning performances and fell actively at the heights $20 \mathrm{~cm}, 40 \mathrm{~cm}$ and $60 \mathrm{~cm}$. Ground reaction force, pressure distribution on feet, and angle of ankle motion during impact from falling were acquired and analyzed synchronously. Results: Compared with ordinary soles, softer soles can effectively reduce the peak impact force during the impact process, prolong the time interval between the first peak and the second peak of the impact force, and at the same time reduce the maximum and maximum intensity of pressure on the plant, increase the area where plant is in contact with sole, and reduce range of motion of ankle. Conclusions: In comparison with sports shoes with ordinary sole, wearing sports shoes with softer sole can effectively reduce intensity of plantar peak pressure, intensity of mean pressure, peak pressure, and play a good role in shock absorption. Therefore, the softer sole of sports shoes can effectively relieve the burden on the feet, enhance the comfort of the feet, and reduce the chance of sports injuries.
\end{abstract}

\section{Introduction}

Falling is one of the most common movements in sports. Some studies show that as the hardness of soles of sports shoes changes, the body's neuron-skeleton-muscle system will adapt to movement (Winnow et al., 2010), thus maintaining the human body's comfort in wearing sport shoes with sole of different hardness, and allowing the human body to feel similar impact and impact loads from falling at the same height (Russell et al., 2012).

While the human body can make itself fall in a safer manner by regulating posture, movement characteristics and neuromuscular feedback of lower limbs falling and other ways (Ly et al., 2010), it is required to bear the ground impact, 3 to 7 times of its weight (Iida et al., 2011), at the initial stage of contact to land. Previous studies show that the great impacts to be borne during falling and force transmission arising thereby are the main causes of sports injury of lower limbs (Quatman et al., 2006). Excessive load may cause acute injuries (such as sprains, fractures, and clumps in the knee joint) (Banana et al., 2011), or overuse injuries, such as force fracture, and patella strains (Bayliss et al., 2016). In the 1970s and 1980s, shock absorbers for sports shoes were proposed (Chang et al., 2012). Researchers and manufacturers attempted to reduce the negative impact of sports shoes on the feet by changing the structural characteristics and materials of soles of the sports shoe. One of the important factors considered was the hardness of soles of the sports shoes (Yeow et al., 2011).

On the other hand, in some studies, the possibility of feet injury was reduced by analysis of characteristics of force on feet from the perspective of force on feet (Sobhani et al., 2014). The study by Chang et al. (2012) confirmed that reducing the force on feet could help reduce exercise-induced feet injury. Study of Xing et al. (2013) analyzed the psychophysical relationship between the magnitude of pressure on thirteen test locations of twenty healthy subjects' feet with four probe areas at three indentation speeds and the corresponding perceived sensations, and it shows that the relationship between the sensory intensity to pressure magnitude appears to follow a modified Stevens' power law with power exponents less than 1.0 and consistent across the 13 test locations with a mean of 0.82 and a range from 0.67 to 0.98. Study of Bayliss et al. (2016) shows that the 
pressure on the plantar parts is distributed evenly, which can effectively reduce the sports injury of feet and can place the key requirements on the functional design of shoes, especially sports shoes.

To sum up, while some literatures have shown differences between sports shoes with soles of different hardness in shock absorption (Queen et al., 2010), it is not clear that which physical indexes can be used to characterize such differences and whether shock absorption for sole is a result of synergy among numerous factors (Wannop et al., 2010). These parts are to be further studied.

On this basis, purpose of this study is to explore impact of sports shoes on force on feet as an additional intervention factor during active falling with a large impact load. Force on feet is mainly presented in three perspectives, ground reaction force, pressure distribution on feet, and angle of ankle motion.

\section{Methods}

\subsection{Subjects.}

12 male undergraduates were selected as subjects. Table 1 shows their basic information. It was confirmed that all subjects were not engaged in strenuous exercise in 24 hours prior to the test. Besides, their lower limbs and feet were free of evident injury in half a year. They were in good physical condition and of high athletic ability. They had mastered falling movements in exercise, understood the purpose of the test and signed written consent.

Table 1. Basic Information of the Subjects

\begin{tabular}{ccccc}
\hline $\mathrm{n}$ & $\begin{array}{c}\text { Age } \\
(\mathrm{yr})\end{array}$ & $\begin{array}{c}\text { Height } \\
(\mathrm{cm})\end{array}$ & $\begin{array}{c}\text { Weight } \\
(\mathrm{kg})\end{array}$ & $\begin{array}{c}\text { Size } \\
(\mathrm{cm})\end{array}$ \\
\hline 12 & $24 \pm 2$ & $176 \pm 2$ & $65 \pm 5$ & 26 \\
\hline
\end{tabular}

\subsection{Instruments for Test.}

Three-dimensional motion force measurement system TrueImpuls (Northern Digital Inc, Canada) was used to acquire vertical ground reaction force at the stage of falling. Such system consists of two pressure sensors $60 \mathrm{~cm}$ long, $40 \mathrm{~cm}$ wide and $10 \mathrm{~cm}$ high, and is provided with signal amplifier externally, of which frequency of acquisition is $1000 \mathrm{HZ}$.

Insole-type force on feet test system (Bioforcen, China) was used to acquire data on static force on feet. Film array pressure sensor of is $4 \mathrm{dot} / \mathrm{cm} 2$ in density of dot matrix, $6 \mathrm{~kg} / \mathrm{cm} 2$ in range and $100 \mathrm{HZ}$ in sampling frequency.

Three-dimensional motion force measurement system, Optotrak ${ }^{\circledR}$ CertusTM/3D investigator (Northern Digital Inc., Canada) was used to acquire angle of ankle motion during falling. Such system consists of positioning sensor, system control unit, concentrator, and marker and controlled PC, detects and captures the specific wavelength emitted by the marker by means of a total of 6 CCD cameras in two sets. Such system can automatically identify location of sensor and acquire and display three-dimensional coordinate data on Marker in a real-time manner by means of First Principle. The maximum lighting frequency of Marker is $4600 \mathrm{~Hz}$. The maximum sampling frequency of such system is $2000 \mathrm{~Hz}$.

\subsection{Test Schemes.}

\subsubsection{Sports Shoes Selection.}

Cushioning performance of shoes is mainly presented in midsole of shoes. Sole mentioned below mainly refers to midsole.

Shoes A: the ordinary shoes with poor cushioning performance in sole and free of midsole materials.

Shoes B: Cushioning performance is ordinary; material of midsole is EVA. That is, the midsole is shaped in one step after the material is injected into mound and heated with high temperature. It is called one-time foamed midsole, also EVA midsole. Its performance in shock absorption is inferior to that of PHYLON midsole. 
Shoes C: Cushioning performance is good; material of midsole is PHYLON. That is, the midsole is shaped after the material is injected into mound and heated twice with high temperature. It is called secondary foamed midsole, also PHYLON midsole.

\subsubsection{Active Falling Test.}

The test covers three falling heights and three kinds of sports shoes. That is, each subject is required to complete 9 tests ( 3 kinds of sports shoes $\times 3$ heights). Break between two tests is 3 min. The heights are $20 \mathrm{~cm}, 40 \mathrm{~cm}$ and $60 \mathrm{~cm}$ respectively. Falling is active. The specific movement of falling: Before jumping, the subject stands with feet in a wooden platform of adjustable height with distance between his feet equal to shoulder. He raises hands to be parallel to ground, jumps with feet forward and keep hands parallel to ground during falling. During falling, his feet are required to be fully located at sensor zone of force platform. Area of such zone is $60 \mathrm{~cm} \times 40 \mathrm{~cm}$. Besides, in order to prevent injury, both knees are bent to a certain angle, which plays a role in buffering, as shown in Fig.1.
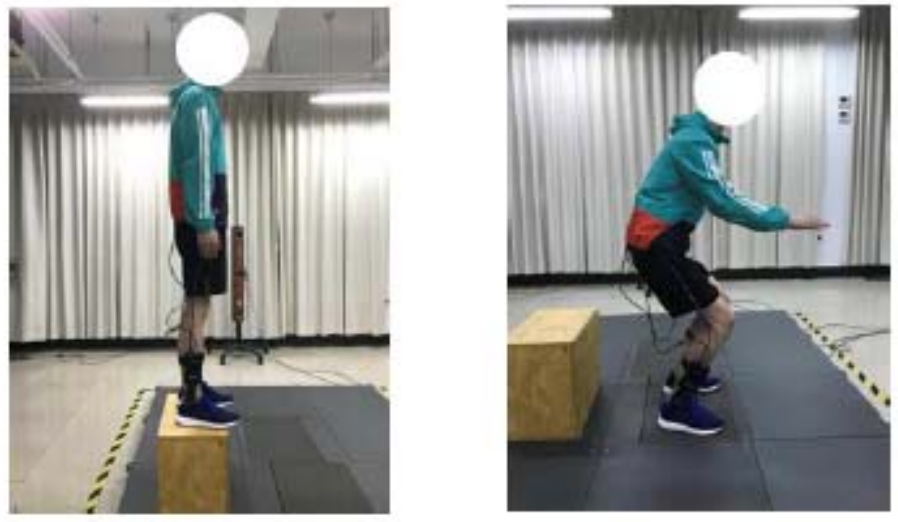

Fig 1. Both knees are bent to a certain angle

\subsection{Evaluation Parameters.}

\subsubsection{Impact force Peak.}

After the human body hits the ground from different heights, sole will be subject to a reaction force vertical to ground (Quitman et al., 2006). For example, in this study, a large impact force will occur in initial contact to ground when subject hits the ground from a height of $60 \mathrm{~cm}$ in shoes A. Such impact force generally covers two peaks, namely the first peak and the second peak of impact force (Fig.2). The first pressure peak occurs when toe hits the ground. Next, the second pressure peak occurs when center of pressure is transmitted to posterior feet. The time interval between the first peak and the second peak of impact force is $23 \mathrm{~ms}$.

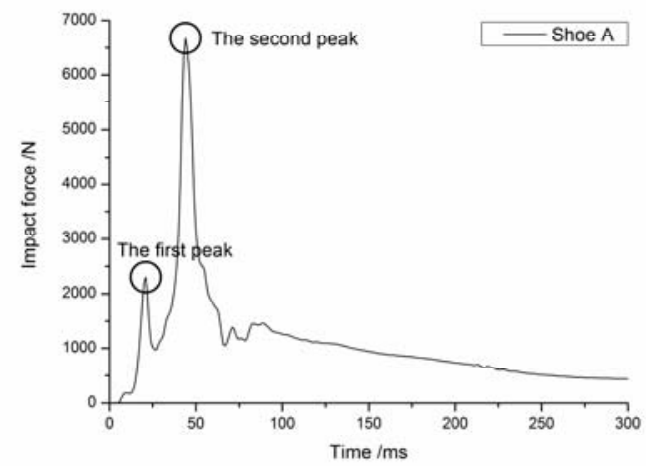

Fig 2. Two peaks of impact force

\subsubsection{Distribution of Force on Feet.}

After the human body hits the ground from a certain height, the first part which bears force is sole, which will be subject to a vertical upward reaction force (Niu et al., 2014). Then such reaction force is transmitted to planta via sole. Since sole is able to not only buffer ground reaction force, but also absorb some energy, due to its viscoelasticity, pressure transmitted to sole is less than reaction force 
which sole bears. For a purpose of analysis, we selected the three most representative indexes, maximum pressure, maximum intensity of pressure and maximum contact area during falling, to be analyzed, as shown in Fig.3.

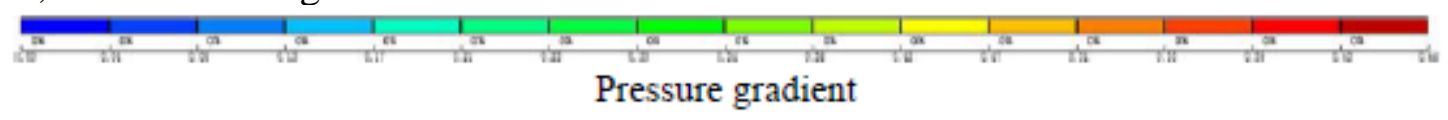

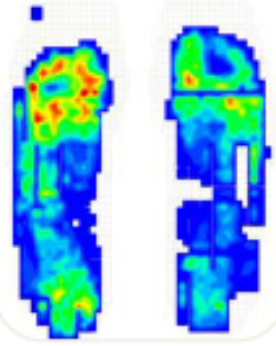

Maximum pressure
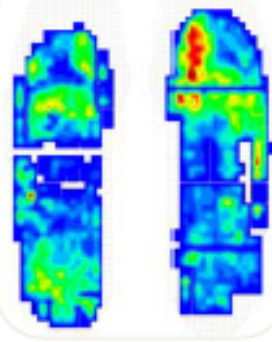

Maximum contact area
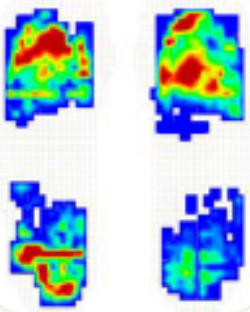

Maximum intensity of pressure

\subsubsection{Range of Motion of Ankle.}

Fig 3. Three most representative indexes

In sagittal plane of shank, one Marker was stuck on external side of shank, ankle and external side of shoes respectively (Fig.4). Marker can be used to record coordinates of such point. These three points can form an angle where ankle is an acme. Such angle is changing all the time. We used range of change in angle to present range of ankle motion. The difference between maximum angle and minimum angle of ankle was calculated at the stage of falling so as to obtain such range of angle.

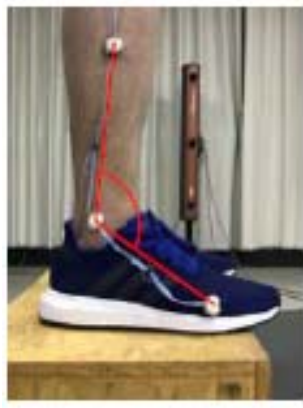

Before landing

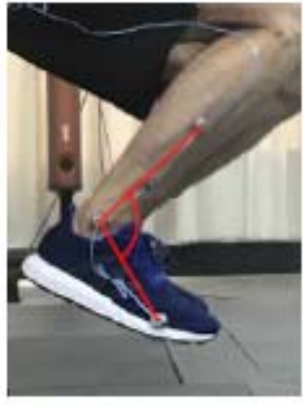

In the air

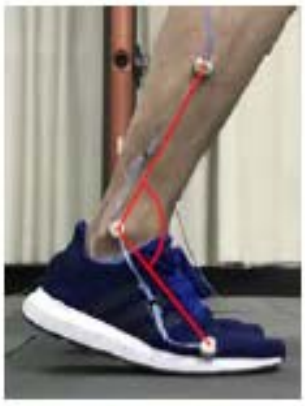

Landing on the forefoot Both feet on the ground

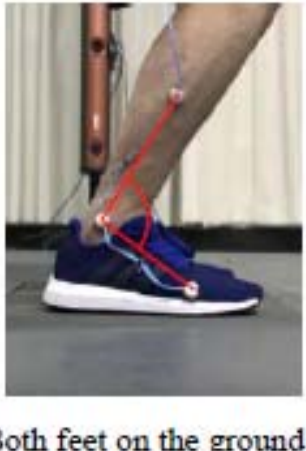

Fig 4. Marker on external side of shank, ankle and external side of shoes respectively

\subsection{Data Processing and Analysis}

The parameter values are all indicated with average \pm standard deviation. Two-way repeated measures (Two-Way Repeated Measures ANOVA, SPSS 21.0) is adopted in this research to observe the influence of independent variables (different falling height $\times$ different soles) on all dependent parameters (impact, planter pressure distribution and the motion of ankle-joint).

The feature data is firstly extracted, including the size for the first pressure peak and the second pressure peak and time interval of the two peak values, and then the difference value between the two peak values is obtained. Plantar data includes maximum pressure, maximum intensity of pressure and maximum contact area. The maximum and minimum for ankle joint angle should be firstly found in the falling process, and then the difference, namely the motion range of ankle joint between them is calculated. Table 2 is obtained after summarizing these data. 
Table 2. Data summary of impact, force on feet distribution and motion range of ankle joint.

\begin{tabular}{|c|c|c|c|c|c|c|c|c|c|c|}
\hline & \multicolumn{4}{|c|}{ Plantar impact } & \multicolumn{3}{|c|}{ Force on feet distribution } & \multicolumn{3}{|c|}{ Motion range of ankle joint } \\
\hline & $\begin{array}{l}\text { The first } \\
\text { peak }(\mathrm{N})\end{array}$ & $\begin{array}{c}\text { The } \\
\text { second } \\
\text { peak }(\mathrm{N})\end{array}$ & $\begin{array}{l}\text { Difference } \\
(\mathrm{N})\end{array}$ & $\begin{array}{l}\text { Time } \\
\text { interval } \\
(\mathrm{ms})\end{array}$ & $\begin{array}{l}\text { Maximum } \\
\text { pressure } \\
(\mathrm{N})\end{array}$ & $\begin{array}{c}\text { Maximum } \\
\text { contact area } \\
\left(\mathrm{cm}^{2}\right)\end{array}$ & $\begin{array}{c}\text { Maximum } \\
\text { intensity of } \\
\text { pressure }(\mathrm{kPa})\end{array}$ & $\begin{array}{l}\text { Maximum } \\
\text { angle }\left(^{\circ}\right)\end{array}$ & $\begin{array}{l}\text { Minimum } \\
\text { angle }\left(^{\circ}\right)\end{array}$ & $\begin{array}{c}\text { Angle } \\
\text { variation } \\
\left({ }^{\circ}\right)\end{array}$ \\
\hline \multirow[t]{3}{*}{ A-shoe 20} & $\begin{array}{c}1135.89 \pm \\
65.13\end{array}$ & $\begin{array}{c}3348.20 \pm \\
125.10\end{array}$ & $\begin{array}{c}2212.31 \pm \\
107.72\end{array}$ & $\begin{array}{c}29.42 \pm \\
2.31\end{array}$ & $\begin{array}{c}2768.05 \pm \\
103.75\end{array}$ & $\begin{array}{c}124.25 \pm \\
8.40\end{array}$ & $\begin{array}{c}291.06 \pm \\
14.55\end{array}$ & $\begin{array}{c}128.75 \pm \\
12.92\end{array}$ & $\begin{array}{c}76.68 \pm \\
5.08\end{array}$ & $\begin{array}{c}52.06 \pm \\
4.13\end{array}$ \\
\hline & $\begin{array}{c}1914.68 \pm \\
138.98\end{array}$ & $\begin{array}{c}4664.85 \pm \\
107.16\end{array}$ & $\begin{array}{c}2750.17 \pm \\
89.29\end{array}$ & $\begin{array}{c}23.75 \pm \\
2.84\end{array}$ & $\begin{array}{c}3060.83 \pm \\
146.04\end{array}$ & $\begin{array}{c}128.58 \pm \\
11.76\end{array}$ & $\begin{array}{c}301.84 \pm \\
12.89\end{array}$ & $\begin{array}{c}135.23 \pm \\
10.73\end{array}$ & $\begin{array}{c}72.02 \pm \\
6.82\end{array}$ & $\begin{array}{c}63.20 \pm \\
3.99\end{array}$ \\
\hline & $\begin{array}{c}2366.02 \pm \\
177.82\end{array}$ & $\begin{array}{c}5237.77 \pm \\
185.76\end{array}$ & $\begin{array}{c}2871.75 \pm \\
130.22\end{array}$ & $\begin{array}{c}22.00 \pm \\
2.55\end{array}$ & $\begin{array}{c}3322.45 \pm \\
97.82\end{array}$ & $\begin{array}{c}130.25 \pm \\
12.38\end{array}$ & $\begin{array}{c}319.48 \pm \\
11.74\end{array}$ & $\begin{array}{c}139.35 \pm \\
10.45\end{array}$ & $\begin{array}{c}59.05 \pm \\
7.51\end{array}$ & $\begin{array}{c}80.30 \pm \\
6.84\end{array}$ \\
\hline B-shoe 20 & $\begin{array}{c}1088.93 \pm \\
123.06\end{array}$ & $\begin{array}{c}3110.28 \pm \\
131.66\end{array}$ & $\begin{array}{c}2021.35 \pm \\
97.09\end{array}$ & $\begin{array}{c}31.40 \pm \\
2.03\end{array}$ & $\begin{array}{c}2484.79 \pm \\
115.47\end{array}$ & $\begin{array}{c}135.04 \pm \\
9.45\end{array}$ & $\begin{array}{c}222.30 \pm \\
15.83\end{array}$ & $\begin{array}{c}138.54 \pm \\
11.64\end{array}$ & $\begin{array}{c}91.14 \pm \\
4.76\end{array}$ & $\begin{array}{c}47.40 \pm \\
4.20\end{array}$ \\
\hline \multirow[b]{3}{*}{ C-shoe 20} & $\begin{array}{c}1829.75 \pm \\
109.63\end{array}$ & $\begin{array}{c}4301.34 \pm \\
142.05\end{array}$ & $\begin{array}{c}2471.59 \pm \\
137.42\end{array}$ & $\begin{array}{c}25.60 \pm \\
2.81\end{array}$ & $\begin{array}{c}2739.67 \pm \\
104.68\end{array}$ & $\begin{array}{c}140.88 \pm \\
12.70\end{array}$ & $\begin{array}{c}224.75 \pm \\
12.77\end{array}$ & $\begin{array}{c}142.32 \pm \\
9.76\end{array}$ & $\begin{array}{c}88.14 \pm \\
5.53\end{array}$ & $\begin{array}{c}54.18 \pm \\
5.07\end{array}$ \\
\hline & $\begin{array}{c}2299.43 \pm \\
120.03\end{array}$ & $\begin{array}{c}4963.14 \pm \\
115.99\end{array}$ & $\begin{array}{c}2663.71 \pm \\
115.72\end{array}$ & $\begin{array}{c}24.27 \pm \\
3.39\end{array}$ & $\begin{array}{c}3028.45 \pm \\
124.85\end{array}$ & $\begin{array}{c}141.25 \pm \\
10.85\end{array}$ & $\begin{array}{c}227.85 \pm \\
16.14\end{array}$ & $\begin{array}{c}144.45 \pm \\
13.89\end{array}$ & $\begin{array}{c}68.70 \pm \\
4.79\end{array}$ & $\begin{array}{c}75.74 \pm \\
4.67\end{array}$ \\
\hline & $\begin{array}{c}1072.58 \pm \\
91.27\end{array}$ & $\begin{array}{c}2945.65 \pm \\
114.79\end{array}$ & $\begin{array}{c}1873.07 \pm \\
148.62\end{array}$ & $\begin{array}{c}32.47 \pm \\
2.29\end{array}$ & $\begin{array}{c}2342.04 \pm \\
82.72\end{array}$ & $\begin{array}{c}138.71 \pm \\
11.69\end{array}$ & $\begin{array}{c}209.07 \pm \\
14.85\end{array}$ & $\begin{array}{c}139.74 \pm \\
12.57\end{array}$ & $\begin{array}{c}94.76 \pm \\
6.21\end{array}$ & $\begin{array}{c}44.99 \pm \\
6.30\end{array}$ \\
\hline 40 & $\begin{array}{c}1662.77 \pm \\
80.04\end{array}$ & $\begin{array}{c}3944.84 \pm \\
83.40\end{array}$ & $\begin{array}{c}2282.07 \pm \\
96.43\end{array}$ & $\begin{array}{c}27.80 \pm \\
2.39\end{array}$ & $\begin{array}{c}2499.49 \pm \\
126.91\end{array}$ & $\begin{array}{c}145.10 \pm \\
9.90\end{array}$ & $\begin{array}{c}214.29 \pm \\
9.73\end{array}$ & $\begin{array}{c}142.98 \pm \\
11.37\end{array}$ & $\begin{array}{c}89.90 \pm \\
4.82\end{array}$ & $\begin{array}{c}53.08 \pm \\
5.74\end{array}$ \\
\hline 60 & $\begin{array}{c}2175.16 \pm \\
94.57\end{array}$ & $\begin{array}{c}4444.48 \pm \\
147.78\end{array}$ & $\begin{array}{c}2269.32 \pm \\
125.95\end{array}$ & $\begin{array}{c}25.33 \pm \\
3.20\end{array}$ & $\begin{array}{c}2759.72 \pm \\
111.67\end{array}$ & $\begin{array}{c}145.75 \pm \\
11.48\end{array}$ & $\begin{array}{c}221.81 \pm \\
11.49\end{array}$ & $\begin{array}{c}145.64 \pm \\
10.94\end{array}$ & $\begin{array}{c}80.84 \pm \\
6.34\end{array}$ & $\begin{array}{c}64.79 \pm \\
4.88\end{array}$ \\
\hline
\end{tabular}

\section{Results}

\subsection{Influence of Sole Hardness on Impact Peak.}

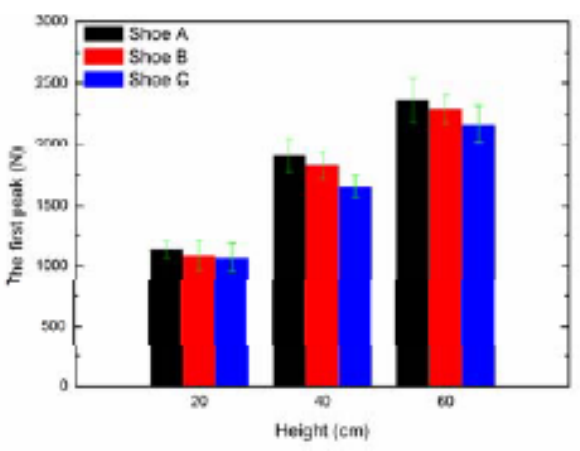

( I )

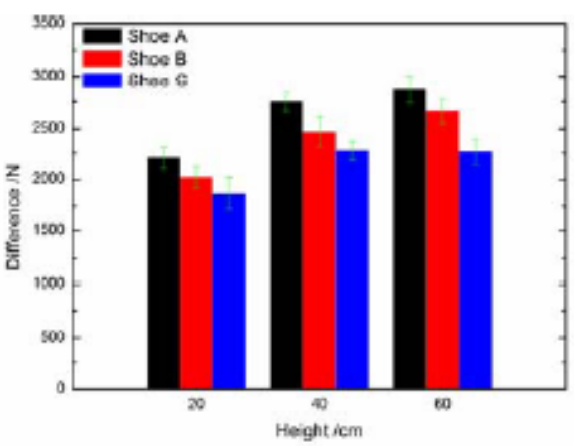

(III)

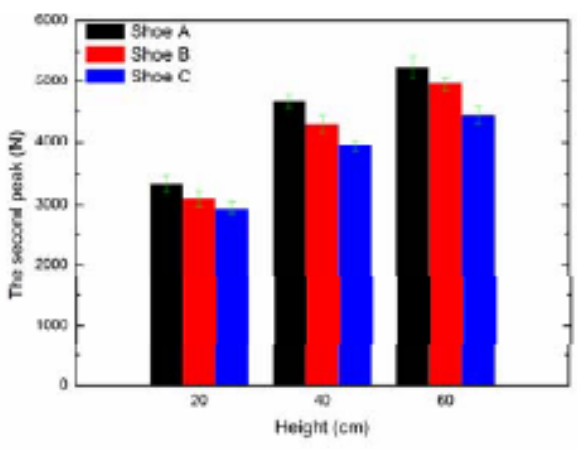

( II )

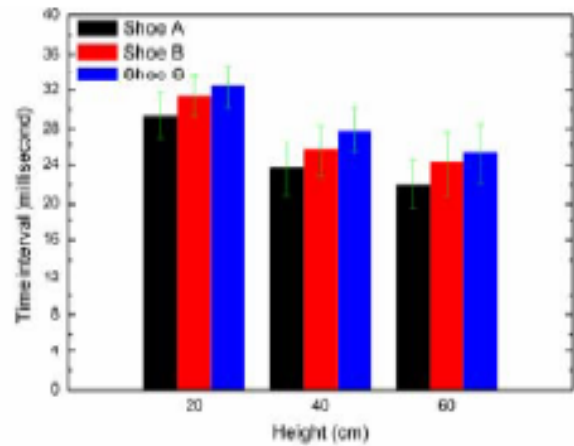

(IV)

Fig 5. Impact change

The peaks (the first peak and the second peak) of vertical ground reaction force for shoe A are always over shoe $\mathrm{B}$, and shoe $\mathrm{C}$ always has the minimum peak in the active falling process. 
Meanwhile, the impact peak difference for three shoes in the same height increases as the height increases, and the impact peak difference for them is minimum in height of $20 \mathrm{~cm}$; in addition, it can be found from parts (I) and (II) in Fig. 5 that impact change rate is reduced.

For difference (III) between the first peak and the second peak of impact, the difference increases as the height increases for the same shoe comprehensively, but the difference for falling in height of $60 \mathrm{~cm}$ is slightly less than that in height of $40 \mathrm{~cm}$. Secondarily, the impact difference for shoe A is bigger than that of shoe $\mathrm{B}$, and shoe $\mathrm{C}$ has the minimum impact difference for the same height.

For the time interval (IV) of two impact peaks, the time interval reduces as height increases for the same shoe, namely the time interval for two impact peaks is reduced as height increases. Secondarily, the time interval for impact peaks of shoe $\mathrm{A}$ is less than that of shoe B in the same height, and shoe $\mathrm{C}$ has the minimum time interval, namely the time interval for the two impact peaks is larger when the sole is softer.

\subsection{Influence of Sole Hardness on Force on Feet and Intensity of Pressure and Contact Area.}

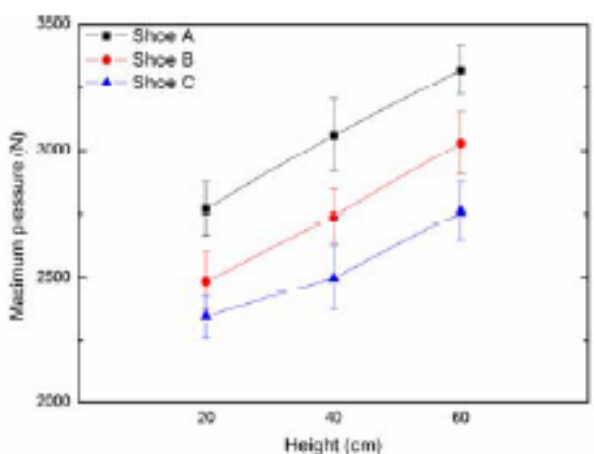

( I )

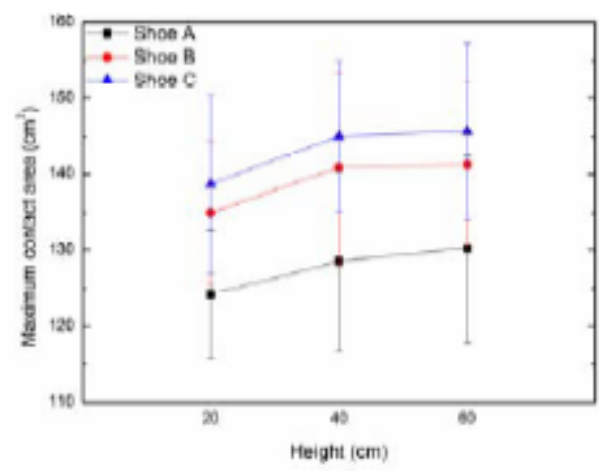

( II )

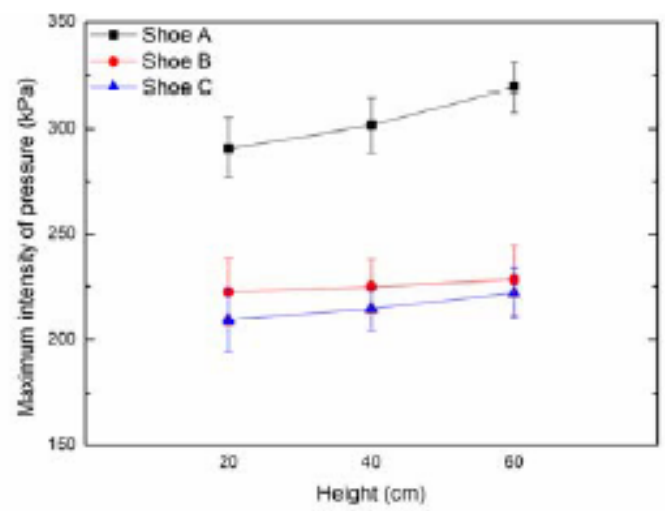

(III)

Fig 6. Maximum force of shoe A, B and C

It can be found from part (I) of Fig. 6 that the maximum force on feet of shoe A is bigger than that of shoe $\mathrm{B}$, and shoe $\mathrm{C}$ has the minimum in the same height; the maximum force on feet for falling in height of $60 \mathrm{~cm}$ is bigger than that in height of $40 \mathrm{~cm}$, and minimum force on feet is for $20 \mathrm{~cm}$ for the same type of shoe. Meanwhile, the increase rate for maximum force on feet from $40 \mathrm{~cm}$ to $60 \mathrm{~cm}$ is bigger than that from $20 \mathrm{~cm}$ to $40 \mathrm{~cm}$ for falling in three heights in shoe C.

For contact area (II) of feet to sole, the maximum contact area for falling in shoe A is less than that in shoe $\mathrm{B}$, and shoe $\mathrm{C}$ has the maximum contact area of feet to sole in the same height. Besides, the maximum contact area of feet to sole for the same shoe increases as height increases, but the increase rate for maximum contact area for falling in the three shoes will all reduce when the height is over 40 $\mathrm{cm}$.

It can be found from part (III) of Fig. 6 that the maximum plantar intensity of pressure for falling in shoe $\mathrm{A}$ is far more than shoe $\mathrm{B}$ and shoe $\mathrm{C}$, and the increase rate for intensity of pressure increases as height increases for falling the same shoe. 


\subsection{Assessment Mode for Sole Buffer Performance.}

The sole can be simplified into a three-element viscos-elastic model because sole has viscos-elasticity, and sole pressure is not equal to force on feet because the pressure and deformation of the model is non-linearly changed; force on feet is less than that of sole pressure, and the difference of the two pressure values can be used to indicate the sole buffer performance, namely the pressure sole buffers off.

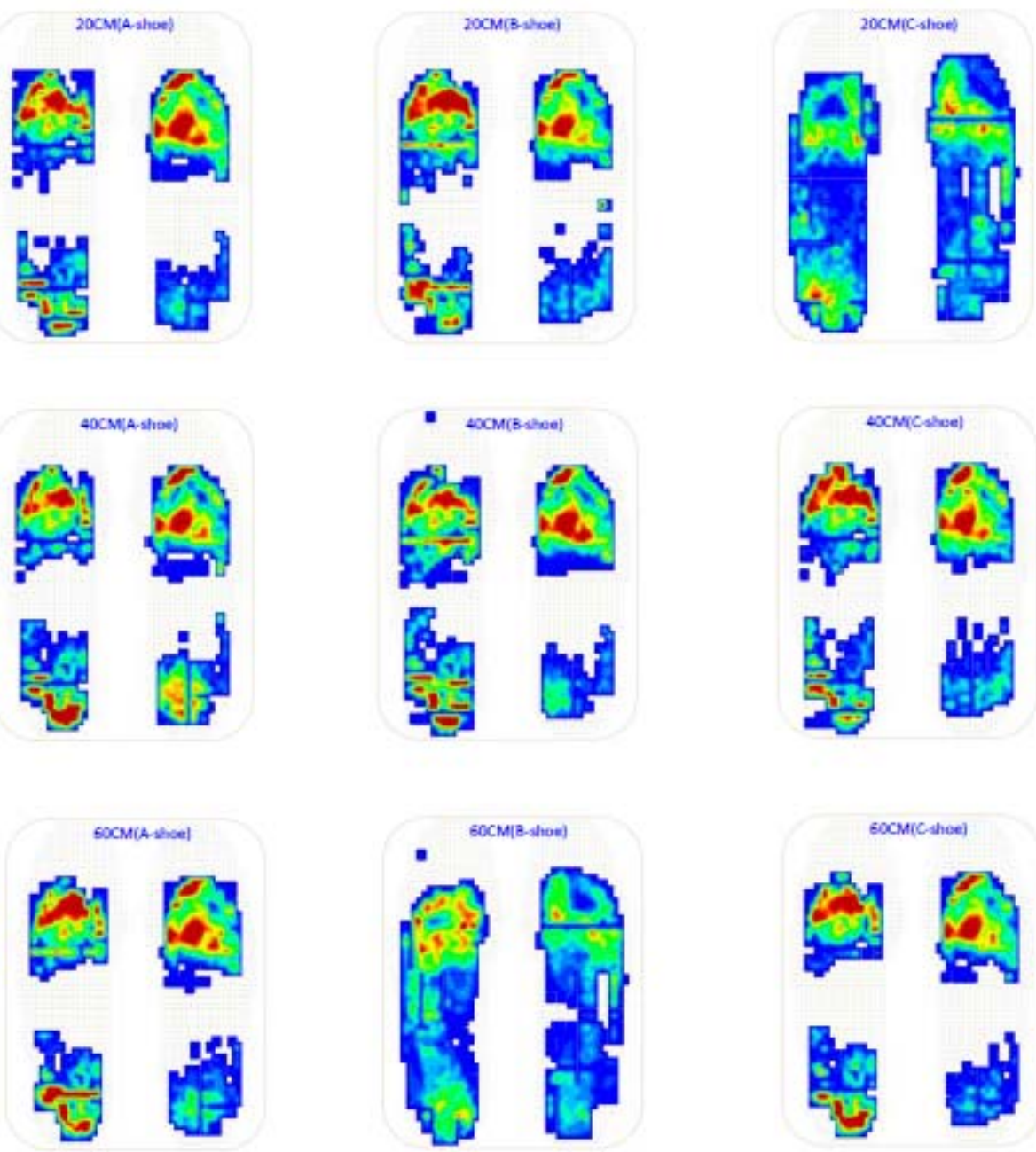

Fig 7. Nine groups of maximum pressure frame image for planter pressure

The data of maximum pressure for sole and feet (shown in Fig. 7) in three shoes in different heights is respectively selected, and the difference is obtained by subtracting the plantar maximum pressure with maximum sole pressure; the ratio of this difference to maximum sole pressure is namely the dissipation ratio of the sole (table 3).

Table 3. Ratio for three sole dissipation impacts

\begin{tabular}{|c|c|c|c|c|c|c|c|c|c|}
\hline \multirow[b]{2}{*}{ Height(cm) } & \multicolumn{3}{|c|}{ Shoe A } & \multicolumn{3}{|c|}{ Shoe B } & \multicolumn{3}{|c|}{ Shoe C } \\
\hline & 20 & 40 & 60 & 20 & 40 & 60 & 20 & 40 & 60 \\
\hline Maximum so & 3348.20 & 4664.85 & 5237.77 & 3110.28 & 4301.34 & 4963.14 & 2945.65 & 3944.84 & 4444.48 \\
\hline Maximum force on feet $(\mathrm{N})$ & 2768.05 & 3060.83 & 3322.45 & 2484.79 & 2739.67 & 3028.45 & 2342.04 & 2499.49 & 2759.72 \\
\hline Differ & 580.15 & 1604.02 & 1915.33 & 625.49 & 1561.67 & 1934.70 & 603.61 & 1445.35 & 1684.76 \\
\hline Dissipation ratio(\%) & 17.33 & 34.39 & 36.57 & 20.11 & 36.31 & 38.98 & 20.49 & 36.64 & 37.91 \\
\hline
\end{tabular}

The dissipation ratio of shoe $\mathrm{C}$ is bigger than that of shoe $\mathrm{B}$, and shoe $\mathrm{A}$ has the minimum dissipation ratio in the same height, namely that the dissipation ratio is bigger when the sole is softer. The dissipation ratio also increases as height increases for the same shoe, but the increase rate for dissipation ratio is reduced as height increases. 


\subsection{Influence of Sole Hardness on Motion Range of Ankle Joint.}

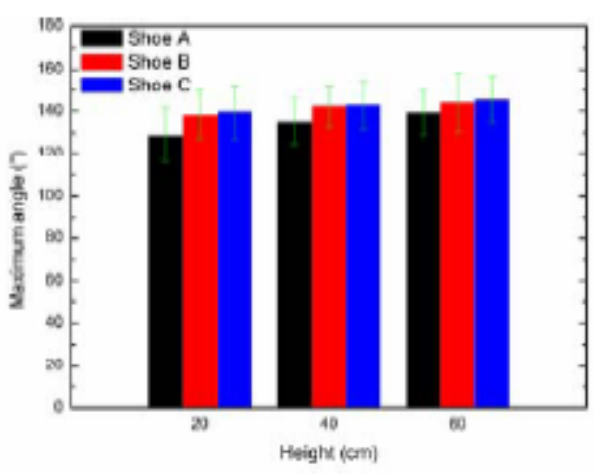

( I )

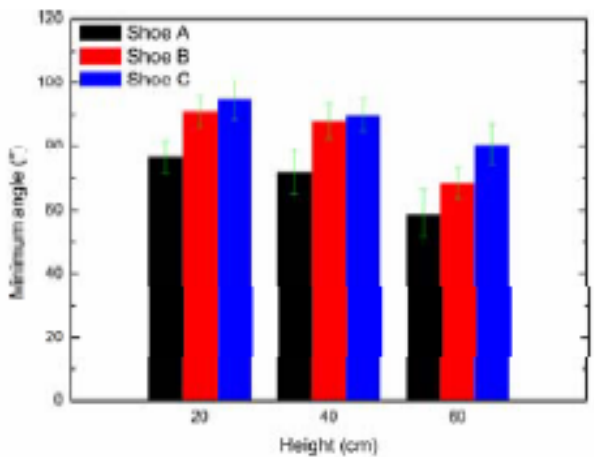

( II )

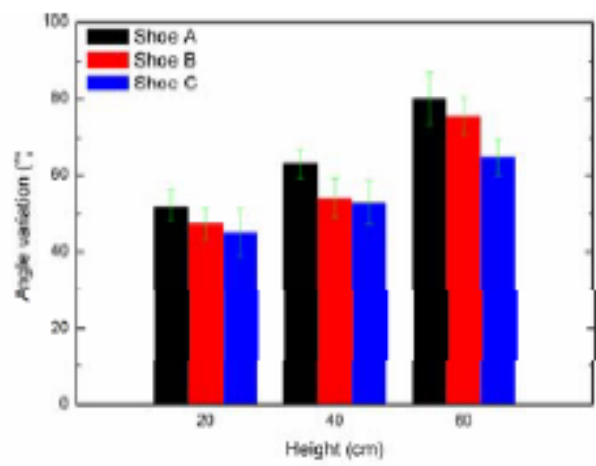

(III)

Fig 8. Minimum angle of ankle joint for shoe $C$ is bigger than that of shoe $B$, and shoe $A$ The maximum angle of ankle joint will increase as height increases, while the minimum angle will reduce as it increases for the same shoe, so the difference of them will increase as height increases, namely that the variation scope of sagittal section angle of ankle joint increases as height increases in the process of active falling to the ground. Secondarily, the maximum angle of ankle joint in shoe $\mathrm{C}$ is bigger than that in shoe $\mathrm{B}$, and shoe $\mathrm{A}$ has the minimum maximum angle for ankle joint in the same height. Furthermore, the minimum angle of ankle joint for shoe $\mathrm{C}$ is bigger than that of shoe $\mathrm{B}$, and shoe A has the minimum value (shown in Fig. 8).

\section{Discussions}

For impact peak, firstly the impact peak is less in the falling process if the sole hardness is less, namely that the sole impact peak can be changed by changing sole material. Secondly, the change rate of impact peak increases when the height reduces in certain scope, and change rate of impact peak reduces when the height is increased to a certain value; the reason is that the vertical ground reaction force of the sole is so small that sole material cannot be fully compressed for $20 \mathrm{~cm}$, and impact peak of the sole also differs because the viscos-elasticity of the three shoes is different (Mills et al., 2010); for example, the compression degree for three sole materials will be increased when the height increases to $40 \mathrm{~cm}$, and the influence of sole viscos-elasticity on impact peak increases as height increases; when height continually increases, for example, the three sole materials have been fully compressed when the height is increased to $60 \mathrm{~cm}$, and the influence of sole viscos-elasticity on impact peak will not continually increase even though impact continually increases (Cortes et al., 2012). The specific falling height for all soles to reach the maximum compression degree cannot be accurately judged because it is only tested in three different heights for the test and the sole material is also different; it should be tested in more heights for further research so as to get the accurate height. For difference of impact peak, the difference between the first peak value and the second peak value for impact is less when the sole is softer, namely that the difference of the two peaks is less. Finally, 
for time interval of two impact peaks, the time interval between two impact peaks is less as height increases for the same sole. It indicates that the duration for pressure center to move backward is shortened, namely that sole buffer duration is shortened, increasing the injury risk (Becker et al., 2014). In addition, the time interval between two impact peaks is bigger when the sole is softer, thus buffer time is increased and injury risk can be reduced.

The maximum force on feet is less when the sole is softer, and the possible reason is different viscos-elasticity for three soles and different sole dissipation pressure, namely that dissipation pressure is more during falling when the sole is softer (Connor and Ire, 2015). Meanwhile, the increase rate for maximum force on feet increases from $40 \mathrm{~cm}$ to $60 \mathrm{~cm}$, and it is because the sole of shoe $\mathrm{C}$ is not fully compressed for $20 \mathrm{~cm}$ and $40 \mathrm{~cm}$; because the viscos-elasticity dissipation pressure is bigger, and the sole is fully compressed when the height is $60 \mathrm{~cm}$, so the influence of the sole viscos-elasticity on pressure will not increase, and then the redundant pressure will directly reach the feet (VanWassenhove et al., 2010). Besides, the maximum contact area of feet to sole is bigger when the sole is softer, and feet is a rugged hook face; only the front feet contacts the sole when feet touches the ground at the beginning, and the feet surface skin is compressed and deformed as pressure increases; the contact area of feet to the sole increases, and the sole is also compressed and deformed meanwhile (Castro et al., 2015); the deformation degree is greater when the sole is softer, so the contact area to the feet will increase. But the variation rule for maximum intensity of pressure and maximum pressure of sole is consistent, namely that the maximum intensity of pressure of the feet is smaller when the sole is softer. On one hand, the maximum pressure of feet is smaller when the sole is softer; on the other hand, softer sole increases contact area of feet to the sole, so the maximum intensity of pressure for feet reduces under their comprehensive influences (Kaisers et al., 2010). But the pressure intensity size of feet is closely linked to plantar comfortable degree (Bruckner et al., 2010), namely the plantar comfortable degree is higher when the average pressure intensity at sole is less. But it does not indicate that it is better if the pressure intensity at sole distribution is more even (Bailys et al., 2016), because the plantar rugged hook face is formed by long-term evolution, and the pressure and pressure intensity needing to be undertaken by different parts in the face are also different (Kaisers et al., 2010); for example, the rear feet and heel are located below the shank bone, and pressure of the whole body reaches feet through the shank bone; so they need to undertake more pressure and pressure intensity than the front feet, and the plantar injury risk will be added on the contrary if it is forced to evenly distribute pressure intensity at sole (Hahn et al., 2014).

The motion range of ankle joint is smaller if the sole is softer in the same height, because the nerve-muscle-skeleton system will properly adjust the falling impact to prevent injury when the body falls to the ground in a certain height, namely that it adapts to plantar impact of different size through bending of knee joint and ankle joint (Quitman et al., 2006) ; the plantar impact is mainly adjusted through nerve-muscle-skeleton system of the human body because the sole is hard when the feet land in shoe A, namely that adjustment is mainly achieved through bending ankle joint; but the sole impact can also be buffered through the sole besides the body adjustment mechanism, because the sole is softer when the feet land in shoe $\mathrm{C}$, so the impact needing to be adjusted by body for soft sole is smaller than that of hard sole, namely the motion range of ankle joint for soft sole is smaller than that of hard sole.

The sole dissipation ratio is used to indicate the sole effect of impact dissipation in this research, and it can be known from the data analysis that the dissipation ratio is bigger when the sole is softer. The dissipation ratio increases as height increases for the same shoe, but the increase rate for dissipation ratio reduces as height increases.

\section{Conclusions}

The purpose of reducing impact peak and pressure intensity at sole can be achieved through the interference of sports shoes, thus further contributing to avoiding potential impact injury, if the falling impact is not (or not totally) moderately adjusted by the human nerve-muscle skeleton system when the body actively lands. Compared with sports shoes with common insole, the plantar peak 
pressure intensity, average pressure intensity and peak pressure can all be effectively reduced through wearing sports shoes with softer insoles, thus good cushioned effect can be obtained. So softer insoles in sports shoes can effectively alleviate feet burden, enhance plantar comfortable degree and reduce sports injury rate based on this. The new thought will be provided for buffer performance evaluation of insoles in sports shoes in this research.

\section{Acknowledgements}

Supported by Shanghai Municipal Science and Technology Commission Local Universities Capacity Building (Number: 18030501400).

\section{References}

[1]. Bailys, A.J., Weatherholt, A.M., Crandall, T.T., Farmer, D.L., McConnell, J.C., Crossley, K.M., Warden, S.J., 2016. Achilles tendon material properties are greater in the jump leg of jumping athletes. J. Musculoskeletal. Neuronal Interact. 16, 105-112.

[2]. Becker, J., Pisciotta, E., James, S., Fostering, L.R., Chou, L.S., 2014. Centre of pressure trajectory differences between shod and barefoot running. Gait Posture 40, 504-509.

[3]. Banana, D.R., Landor, K.B., Men, H.B., 2011. Pressure-relieving properties of various shoe inserts in older people with plantar heel pain. Gait Posture 33, 385-389.

[4]. Bruckner, K., Oden Wald, S., Schwanitz, S., Heidenfelder, J., Milan, T., 2010. Polyurethane-foam Midsoles in Running Shoes - Impact Energy and Damping, in: Sabo, A., Kafka, P., Lichtenberger, S., Sabo, C. (Eds.), Engineering of Sport 8: Engineering Emotion - 8th Conference of the International Sports Engineering Association. Elsevier Science Be, Amsterdam, pp. 2789-2793.

[5]. Castro, M.P., Figueiredo, M.C., Abreu, S., Sousa, H., Machado, L., Santos, R., Vilas-Boas, J.P., 2015. The influence of gait cadence on the ground reaction forces and plantar pressures during load carriage of young adults. Appl. Ergon. 49, 41-46.

[6]. Chang, J.S., Kwon, Y.H., Kim, C.S., Han, S.H., Park, S.H., 2012. Differences of ground reaction forces and kinematics of lower extremity according to landing height between flat and normal feet. J. Back Musculoskeletal. Retail. 25, 21-26.

[7]. Connor, P.C., Ire, 2015. Comparing and Combining Underfoot Pressure Features for Shod and Unshod Gait Biometrics. Ire, New York. Cortes, N., Morrison, S., Van Lunen, B.L., Onate, J.A., 2012. Landing technique affects knee loading and position during athletic tasks. J. Sci. Med. Sport 15, 175-181.

[8]. Hahn, T., Carl, H.D., Jendrissek, A., Berm, M., Slobodan, B., Rommel, P., Pause, J., 2014. Assessment of Plantar Pressure in Hindfoot Relief Shoes of Different Designs. J. Am. Podiatry. Med. Assoc. 104, 19-23.

[9]. Iida, Y., Kamahis, H., Indaba, Y., Nakazawa, K., 2011. Activity modulations of trunk and lower limb muscles during impact-absorbing landing. J. Electromyogr. Kinesiol. 21, 602-609.

[10]. Kaisers, N.L.W., Stolwijk, N.M., Pataki, T.C., 2010. Linear dependence of peak, mean, and pressure-time integral values in plantar pressure images. Gait Posture 31, 140-142.

[11]. Ly, Q.H., Alou, A., Enricher, S., Bali, L., 2010. Towards a footwear design tool: Influence of shoe midsole properties and ground stiffness on the impact force during running. J. Biotech. 43, 310-317. 
[12]. Mills, C., Yeadon, M.R., Pain, M.T.G., 2010. Modifying landing mat material properties may decrease peak contact forces but increase forefoot forces in gymnastics landings. Sports Biomechanics 9, 153-164.

[13]. Nia, W.X., Feng, T.A., Jiang, C.H., Zhang, M., 2014. Peak Vertical Ground Reaction Force during Two-Leg Landing: A Systematic Review and Mathematical Modelling. Biomed Res. Int., 10 .

[14]. Quitman, C.E., Ford, K.R., Myer, G.D., Hewett, T.E., 2006. Maturation leads to gender differences in landing force and vertical jump performance - A longitudinal study. Am. J. Sports Med. 34, 806-813.

[15]. Queen, R.M., Abbey, A.N., Wiegerinck, J.I., Yoder, J.C., Nutley, J.A., 2010. Effect of shoe type on plantar pressure: A gender comparison. Gait Posture 31, 18-22.

[16]. Russell, M.E., Butler, R.J., Nutley, J.A., Queen, R.M., 2012. Effect of Shoe Type and Gender on Loading during a Jump Landing Task. J. Gen. Intern. Med. 27, 424-424.

[17]. Sob Hani, S., van den Heave, E., Bedewed, S., Kluitenberg, B., Postman, K., Hymans, J.M., Dekker, R., 2014. Effect of rocker shoes on plantar pressure pattern in healthy female runners. Gait Posture 39, 920-925.

[18]. VanWassenhove, A., Messer, A.J., Linden, D.V., Cronin, B., Miner, R.L., 2010. Changes in Jumping and Agility Tests Following Sports Performance Training in Youth Athletes: A Retrospective Study. Med. Sci. Sports Exec. 42, 717-717.

[19]. Winnow, J.W., Sorbets, J.T., Stefanyshyn, D.J., 2010. Footwear Traction and Lower Extremity Joint Loading. Am. J. Sports Med. 38, 1221-1228.

[20]. Xing, S.P., Goonetilleke, R.S., Rodrigo, W., Zhao, J.H., 2013. A model for the perception of surface pressure on human foot. Appl. Ergon. 44, 1-10.

[21]. Yew, C.H., Lee, P.V.S., Goh, J.C.H., 2011. Shod landing provides enhanced energy dissipation at the knee joint relative to barefoot landing from different heights. Knee 18, 407-411. 